\title{
Chemical classification of emeralds: A framework for discussing the origin of emerald deposits
}

\author{
G. NELSON EBY ${ }^{1}$
}

${ }^{1}$ Department of Environmental, Earth and Atmospheric Sciences, University of Massachusetts, Lowell, MA, 01854, USA (nelson_eby@uml.edu)

Thirty emerald crystals from 13 emerald deposits were analyzed using instrumental neutron activation analysis (INAA). The emerald classification scheme of Giuliani et al. [1] is used as the framework for the rationalization of the chemical data.

Logarithmic x-y plots using $\mathrm{Cs}, \mathrm{Na}, \mathrm{Rb}, \mathrm{Ga}, \mathrm{Fe}, \mathrm{Sc}, \mathrm{Co}, \mathrm{As}$ and $\mathrm{Sb}$, and a three component $\mathrm{Cr}-\mathrm{Cs}-\mathrm{V}$ plot, effectively differentiate the emerald types.

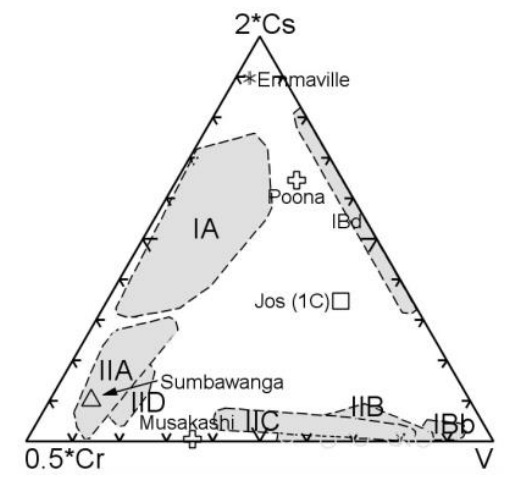

Fig. 1: Cr-Cs-V diagram showing the different emerald groups. Type designations are from Giuliani et al. [1].

Type I, which comprises the largest number of emerald deposits, can be subdivided on the basis of the $\mathrm{Cr} / \mathrm{V}$ ratio. Rare earth element (REE) data can be used to differentiate between magmatic sources that gave rise to the Type I emerald deposits. High Cs is associated with S-type granite and low Cs with alkaline granite sources for the emerald-forming solutions.

Type IIB emeralds have REE patterns very similar to the host black shales illustrating that this lithology is the source of the emerald-forming solutions.

On all the discriminat diagrams there are two apparent endmembers, Type IA and Type IIB. The Type IIA, IIC, and IID emerald deposits tend to plot between these end members. REE and other data indicate a complex interplay between the fluids forming these mineral deposits and the country rock.

[1] Giuliani et al. (2019) Minerals 9, 105 